\title{
ANALISIS KEKUATAN DESAIN STRUKTUR BASE MESIN INDUK CNC VERTIKAL
}

\author{
Arif Krisbudiman'), Barep Luhur Widodo ${ }^{2)}$ \\ 1) Dosen Universitas Pamulang Fakultas Teknik Program Studi Teknik Industri \\ 2) Perekayasa Pertama Balai Teknologi Mesin Perkakas Produksi dan Otomasi Gedung PUSPIPTEK \\ Email :
}

\begin{abstract}
ABSTRAK
Industri manufaktur merupakan salah satu penyokong utama pertumbuhan ekonomi di negara maju. Industri manufaktur yang kuat, akan mampu mendorong produksi barang teknik (komponen mesin, otomotif, dll) yang kemudian dapat di-eksport atau dipakai untuk menggantikan kebutuhan import. Hal ini tentu akan menghasilkan dan menghemat devisa. Salah satu kebutuhan industri manufaktur adalah adanya mesin perkakas sebagai barang modalnya. Nilai import mesin perkakas nasional tahun 2013 sebesar US\$ 1.2 Milyar USD, dan pada tahun 2016 sudah mencapai 1.5 Milyar USD, diantaranya untuk import mesin milling \& bubut. Dalam rangka itu, sejak tahun 2016, BPPT - BT MEPPO sudah mengembangkan mesin perkakas CNC (Milling \& Bubut), dengan kualitas sesuai standar ISO dan sudah mengalami pengujian yang menyeluruh untuk mengurangi ketergantungan terhadap import luar negeri. Pengembangan mesin perkakas sangat dibutuhkan untuk menunjang dunia industri, saat ini BPPT - BT MEPPO BPPT mengembangkan mesin perkakas khususnya mesin induk CNC vertikal. Aspek penting dalam merancang mesin induk CNC vertikal salah satunya adalah perancangan struktur base yang mampu menahan beban statis dari komponen mesin yang lain. Struktur base mesin induk CNC vertikal yang dikembangkan oleh BT MEPPO adalah memodifikasi desain base mesin milling yang lebih besar disesuaikan dengan beban kerja yaitu untuk melakukan proses mesin CNC lainnya. Proses perancangan dilakukan menggunakan metode riset \& development untuk analisis kekuatan struktur desain base sehingga didapat kriteria statik berupa defleksi dan tegangan von mises untuk memastikan desain struktur mesin induk CNC vertikal aman untuk digunakan.
\end{abstract}

Kata kunci: analisis kekuatan, base mesin induk CNC vertikal, defleksi, von mises.

\section{PENDAHULUAN}

Tujuan utama dari teknologi manufaktur adalah untuk memproduksi komponen yang sepresisi mungkin sesuai dengan desain teknik dalam waktu singkat dengan biaya yang murah. Oleh karena itu perlu dikembangkan desain mesin perkakas yang murah dari segi biaya produksi namun tetap memenuhi standard mesin perkakas sebagaimana mestinya.

Masalah yang sering dihadapi dalam proses pengembangan mesin perkakas adalah pengujian secara fisik prototype mesin tersebut, karena proses tersebut membutuhkan waktu dan biaya yang tidak sedikit. Pada Gambar 1 ditampilkan perbandingan antara proses pengembangan sebuah mesin secara konvensional dan dengan menggunakan software analisis atau bisa kita sebut prototipe virtual.

Software analisis menggunakan simulasi komputer menghasilkan pendekatan analisa secara komputerisasi terhadap hasil pengujian prototipe secara langsung. Prototipe virtual tersebut akan diuji dan dianalisa hingga mendapatkan hasil yang optimal atau sesuai dengan performa yang diinginkan, sehingga biaya dan waktu yang dikeluarkan dapat dikurangi jika dibandingkan dengan perancangan konfensional yang melibatkan proses penggantian desain dan penggantian prototipe sebelum akhirnya mesin tersebut beroperasi. Hasil dari simulasi prototipe virtual tersebut dapat menjadi dasar dalam membuat dan menentukan spesifikasi desain 
prototipe yang nantinya akan diuji performa mesin tersebut sebelum diproduksi.

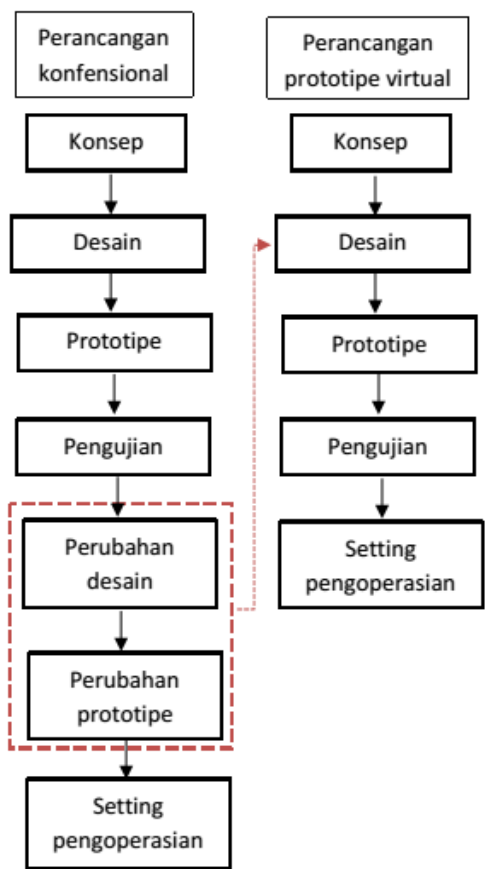

Gambar 1. Perbandingan Perancangan Konvensional dan Virtual

Dengan menggunakan metode simulasi komputasi tersebut Badan Pengkajian dan Penerapan Teknologi - Balai Teknologi Mesin Perkakas, Produksi, dan Otomasi (disingkat BPPT - BT MEPPO) melakukan proses riset $\&$ development (pengembangan) dari desain struktur base mesin induk CNC vertikal yang dirancang oleh BT MEPPO. Target dari produk ini adalah mesin induk $\mathrm{CNC}$ vertikal yang dihasilkan dapat digunakan untuk membuat mesin CNC lainnya dengan aman sesuai spesifikasi teknis dan standar, sehingga mempunyai kualitas yang sama dengan produk sejenis buatan luar negeri di pasaran dan mampu bersaing dengan mesin buatan luar negeri.

\section{DASAR TEORI}

Base merupakan komponen dari mesin induk $\mathrm{CNC}$ vertikal yang berperan dalam pergerakan sumbu $\mathrm{X}$ dan menjadi penopang komponen Saddle dan Table serta Benda Kerja diatasnya. Spesifikasi utama dari mesin induk CNC vertikal pada Tabel 1 berikut:

Tabel 1. Spesifikasi Utama Mesin Induk CNC Vertikal

\begin{tabular}{|c|c|c|}
\hline \multicolumn{2}{|r|}{ Spesifikasi } & Mesin Induk CNC Vertikal \\
\hline \multirow{3}{*}{ Langkah } & Sumbu X & $1500 \mathrm{~mm}$ \\
\hline & Sumbu Y & $900 \mathrm{~mm}$ \\
\hline & Sumbu Z & $800 \mathrm{~mm}$ \\
\hline \multirow{3}{*}{ Meja } & Dimensi Meja & $1500 \times 1000 \mathrm{~mm}$ \\
\hline & $\begin{array}{l}\text { Massa Maksimal } \\
\text { Benda Kerja }\end{array}$ & $2000 \mathrm{~kg}$ \\
\hline & $\begin{array}{l}\text { Kecepatan Operasi } \\
\text { Spindel }\end{array}$ & $6000 \mathrm{rpm}$ \\
\hline \multirow[t]{4}{*}{ Motor } & Motor Spindel & $\begin{array}{c}11 \text { kW AC Spindle Motor } \\
\text { Servo }\end{array}$ \\
\hline & Feed Motor & 4,3 kW AC Servo Motor \\
\hline & Berat Total Mesin & $7000 \mathrm{~kg}$ \\
\hline & $\begin{array}{l}\text { Dimensi Total } \\
\text { Mesin }\end{array}$ & $\begin{array}{c}(\mathrm{W} \times \mathrm{D} \times \mathrm{H})=(2640 \times 2220 \times \\
2070 \mathrm{~mm})\end{array}$ \\
\hline
\end{tabular}

Komponen Saddle terletak diatas Base dan dihubungkan dengan system Boxway, dimana pergerakkan sumbu X-nya menggunakan mekanisme Ballscrew yang diputar oleh motor. Fungsi dasar komponen Base (Gambar 2) adalah sebagai tumpuan pergerakkan sumbu X dari Saddle, Table dan Benda Kerja diatasnya.

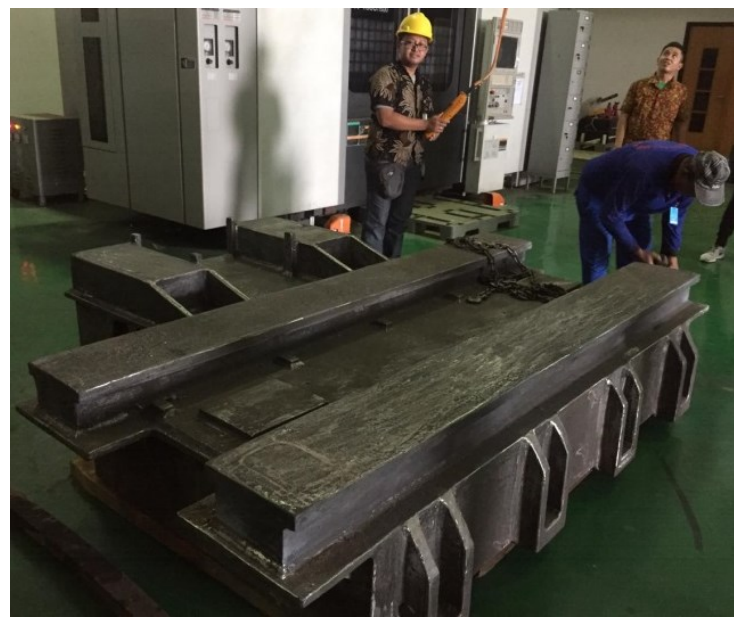

Gambar 2. Base Komponen dari Mesin Induk CNC Vertikal

Material dari komponen Base adalah menggunakan grey cast iron, yaitu FC 20 yang pembuatannya melalui proses pengecoran (casting). Dan Tabel $\mathbf{2}$ berikut adalah komposisi dari grey cast iron (FC) :

Tabel 2. Spesifikasi Utama Mesin Induk CNC Vertikal 


\begin{tabular}{|c|c|c|c|c|c|}
\hline \multicolumn{6}{|c|}{$\begin{array}{l}\text { Range of Compositions for Typical Unalloyed Cast Irons } \\
\text { Nalues in Percent (\%)) }\end{array}$} \\
\hline $\begin{array}{c}\text { Type of } \\
\text { ron }\end{array}$ & Carton & Silicon & Manganese & Sulfur & Phosphorus \\
\hline Gray & 25.4 .0 & $1.0-3.0$ & $02 \cdot 1.0$ & $0.02-0.25$ & $0.02 \cdot 1.0$ \\
\hline Ductile & $3.0-4.0$ & 18.28 & $0.1 \cdot 1.0$ & $0.01-0.03$ & $0.01-0.1$ \\
\hline Compacted Graphite & 25.40 & $1.0 \cdot 3.0$ & $02 \cdot 1.0$ & $0.01-0.03$ & $0.01 \cdot 0.1$ \\
\hline \begin{tabular}{|l} 
Malleable \\
(Cast Whitte)
\end{tabular} & 20.29 & 09.19 & $0.15 \cdot 1.2$ & $0.02 \cdot 0.2$ & $0.02 \cdot 0.2$ \\
\hline White & 18.3 .6 & $05 \cdot 19$ & $0.25 \cdot 0.8$ & $0.06-0.2$ & $0.06-0.2$ \\
\hline
\end{tabular}

Sifat mekanik dari FC 20 yang merupakan kedalam kelompok besi tuang kelabu (grey cast iron) adalah pada Tabel 3 berikut:

Tabel 3. Sifat Mekanik Material Grey Cast Iron

\begin{tabular}{|c|c|c|c|c|c|}
\hline \multirow{2}{*}{\multicolumn{2}{|c|}{ Cast iron }} & \multicolumn{4}{|c|}{ Properties } \\
\hline & & $\begin{array}{l}\text { Tensile strength } \\
\mathrm{MNm}^{-2}\end{array}$ & $\begin{array}{l}\text { Yield strenghth } \\
\mathrm{MNm}^{-2}\end{array}$ & $\begin{array}{l}\text { Elongation } \\
\quad \%\end{array}$ & $\begin{array}{l}\text { Hardness } \\
\mathrm{BHN}\end{array}$ \\
\hline \multicolumn{2}{|l|}{ White cast iron } & $150-500$ & & \multirow[b]{3}{*}{$1.5-1.0$} & $350-500$ \\
\hline \multicolumn{2}{|l|}{ Grey cast iron } & $150-400$ & & & $150-320$ \\
\hline \multicolumn{2}{|l|}{ Chilled iron } & $200-300$ & & & $200-400$ \\
\hline \multicolumn{2}{|l|}{ Mechanite iron } & $250-400$ & & $15-10$ & $175-330$ \\
\hline \multicolumn{2}{|c|}{ Compacted Graphite iron } & $260-415$ & $195-345$ & $3-1$ & $190-270$ \\
\hline \multicolumn{2}{|c|}{$\begin{array}{l}\text { Ferritic malleable iron } \\
\text { (annealed) }\end{array}$} & 365 & 240 & 18 & 130 \\
\hline \multicolumn{2}{|c|}{ Pearlitic malleable iron (anneal) } & 415 & 300 & 10 & 170 \\
\hline \multirow{2}{*}{\multicolumn{2}{|c|}{$\begin{array}{l}\text { Nodular Cast iron, cast } \\
\text { annealed }\end{array}$}} & 550 & 380 & 10 & 190 \\
\hline & & 450 & 310 & 16 & 160 \\
\hline \multicolumn{2}{|l|}{ Ni-hard } & & & 2 & $450-650$ \\
\hline \multicolumn{2}{|l|}{ Ni-hesith } & $247-485$ & & $2-20$ & $100-250$ \\
\hline \multicolumn{3}{|l|}{\begin{tabular}{|l|} 
Metals \\
\end{tabular}} & \multicolumn{3}{|c|}{ Young's Modulus (GPa) Yield Strength (MPa) } \\
\hline \multirow[t]{7}{*}{\begin{tabular}{|l|} 
Ferrous metals \\
\end{tabular}} & \multirow{2}{*}{\multicolumn{2}{|c|}{$\begin{array}{l}\text { Cast iron, ductile (nodular) } \\
\text { Cast iron, grey }\end{array}$}} & \multicolumn{2}{|c|}{\begin{tabular}{|l|l|}
$170-180$ & 250 \\
\end{tabular}} & $250-680$ \\
\hline & & & \multicolumn{2}{|l|}{$80-140$} & $140-420$ \\
\hline & \multicolumn{2}{|c|}{$\begin{array}{l}\text { High carbon steel } \\
\end{array}$} & $200-220$ & $400-$ & \\
\hline & \multicolumn{2}{|c|}{ Low alloy steel } & $210-220$ & $400-$ & \\
\hline & Low cart & on steel & $200-220$ & 250 & \\
\hline & Medium & arbon steel & $200-220$ & $310-$ & \\
\hline & Stainless & teel & $190-210$ & 170 & \\
\hline Nonferrous & \begin{tabular}{|l} 
Aluminiu \\
\end{tabular} & nalloys & $68-82$ & $30-5$ & \\
\hline & Coppera & loys & $110-150$ & $30-5$ & \\
\hline & Lead allo & & $13-15$ & $8-14$ & \\
\hline & Magnesil & malloys & $42-47$ & $70-4$ & \\
\hline & Nickel al & & $190-220$ & $70-1$ & \\
\hline & Silver & & $69-73$ & $190-$ & \\
\hline & Tin & & $41-45$ & $7-15$ & \\
\hline & Titanium & lloys & $90-120$ & 250 & \\
\hline & Tungsten & alloys & $310-380$ & 530 & \\
\hline & Zinc allo & & $68-95$ & $80-4$ & \\
\hline
\end{tabular}

Permasalahan dalam desain dan membangun mesin dapat diselesaikan dilakukan dengan 2 cara numerik dan matematis. Jika benda-benda tersebut mempunyai bentuk yang tidak beraturan atau bisa disebut elemen isoparametri. Maka akan sangat sulit memecahkanya dengan metode matematis, sehingga perlu dilakukan analisis numerik untuk memecahkan permasalahan tersebut yang biasa disebut metode elemen hingga (finite element method).

Metode elemen hingga (FEM) adalah metode yang paling banyak digunakan untuk menyelesaikan masalah model teknik dan matematika. Area masalah tipikal yang diminati meliputi bidang analisis struktural, perpindahan panas, aliran fluida, transportasi massa, dan potensial elektromagnetik. FEM adalah metode numerik tertentu untuk menyelesaikan persamaan diferensial parsial dalam dua atau tiga variabel ruang (yaitu, beberapa masalah nilai batas). Untuk memecahkan masalah, FEM membagi sistem besar menjadi bagian yang lebih kecil dan lebih sederhana yang disebut elemen hingga. Ini dicapai dengan diskritisasi ruang tertentu dalam dimensi ruang, yang diimplementasikan dengan konstruksi jaring objek: domain numerik untuk solusi, yang memiliki jumlah titik yang terbatas (Robert D.Cook, 1990). Rumusan metode elemen hingga dari masalah nilai batas akhirnya menghasilkan sistem persamaan aljabar. Metode ini mendekati fungsi yang tidak diketahui melalui domain. Persamaan sederhana yang memodelkan elemen hingga ini kemudian dirangkai menjadi sistem persamaan yang lebih besar yang memodelkan keseluruhan masalah. FEM kemudian menggunakan metode variasional dari kalkulus variasi untuk mendekati solusi dengan meminimalkan fungsi kesalahan terkait (Weaver,1993)..

Hamper Semua benda mempunyai sifat elastisitas, suatu acuan Analisa struktur benda yang digunakan untuk mengemban beberapa fungsi tertentu, sekaligus menahan gaya luar yang ada. Jika gaya luar dapat menimbulkan perubahan bentuk atau deformasi, kemudian jika gaya tersebut dilepas, dan benda tersebut kembaliApabila gaya luar yang menghasilkan perubahan bentuk (deformation) kemudian gaya tersebut dilepas, dan benda tersebut Kembali seperti semula, hal tersebut karena bahan tersebut mempunyai sifat elastisitas.

Dalam teknik, deformasi mengacu pada perubahan ukuran atau bentuk suatu benda.. Lalu Defleksi adalah perubahan relatif dalam perpindahan eksternal pada suatu benda. Regangan adalah perubahan internal relatif dalam bentuk material kubus yang sangat kecil dan dapat dinyatakan sebagai perubahan nondimensi dalam panjang atau sudut distorsi kubus. Regangan terkait dengan gaya yang bekerja pada kubus, yang dikenal sebagai tegangan, oleh kurva tegangan-regangan. Hubungan antara tegangan dan regangan umumnya linier dan dapat dibalik sampai titik 
leleh dan deformasi. Deformasi ada dua macam, deformasi yang tetap ada bahkan setelah gaya yang diterapkan dihilangkan, sedangkan deformasi sementara dapat dipulihkan walaupun menghilangkan gaya yang diterapkan terhadap material tersebut Deformasi sementara disebut juga deformasi elastik, sedangkan deformasi permanen disebut deformasi plastis.

Sifat elastisitas adalah kemampuan suatu benda untuk menahan pengaruh distorsi dan mengembalikan kembali ke ukuran dan bentuk aslinya ketika pengaruh atau gaya itu dihilangkan., namuk karena batas antara tegangan elastis dan plastis sangat sulit untuk ditemukan. Oleh karena sering disebut dengan kekuatan luluh (yield point). Kekuatan luluh adalah perubahan bentuk properti suatu bahan yang teganganya mengenai titik leleh yaitu kondisi bahan plastis. Kekuatan Tarik adalah tegangan maksimum yang dapat ditahan material saat diregangkan atau ditarik sebelum pecah. Pada material getas kekuatan tarik mendekati titik leleh, sedangkan pada material yang lentur kekuatan tarik ultimit bisa lebih tinggi.

Pada dasarnya tegangan dapat didefinisikan sebagai besaran gaya yang bekerja pada suatu satuan luas. Secara matematis definisi tersebut dapat ditulis sebagai berikut:

$$
\text { Tegangan }(\sigma)=\frac{F}{A}
$$

Dimana:

$$
\begin{aligned}
\sigma= & \text { Tegangan normal }\left[\mathrm{N} / \mathrm{m}^{2}\right] \\
\mathrm{F}= & \text { Gaya yang bekerja tegak lurus } \\
& \text { bidang }[\mathrm{N}] \\
\mathrm{A}= & \text { Luas bidang }\left[\mathrm{m}^{2}\right]
\end{aligned}
$$

Pada suatu bidang yang dikenal suatu gaya akan terdapat dua jenis tegangan yang mempengaruhi bidang tersebut, yaitu :

Tegangan Normal adalah tegangan yang tegak lurus terhadap permukaan benda yang ditimbulkan oleh gaya aksial dan momen lentur.

Tegangan Geser adalah tegangan yang sejajar terhadap permukaan benda yang ditimbulkan oleh gaya geser dan gaya puntir dan torsi.

Tegangan normal, secara matematis dapat didefinisikan sebagai berikut:

$$
\sigma=\operatorname{Lim} \frac{\Delta F}{\Delta A}
$$

Tegangan normal terbagi menjadi dua macam, yaitu Tegangan normal yang menghasilkan suatu tarikan (tension) pada permukaan suatu benda. Tegangan normal yang menghasilkan suatu dorongan (compression) pada permukaan benda.

Komponen lain dari intensitas gaya yang bekerja sejajar dengan bidang dari luas elemen adalah tegangan geser yang dilambangkan dengan $\tau$, yang secara matematis didefinisikan sebagai berikut:

$$
\tau=\operatorname{Lim} \frac{\Delta V}{\Delta A}
$$

Dimana:

$$
\begin{aligned}
& \tau=\text { Tegangan geser }\left[\mathrm{N} / \mathrm{m}^{2}\right] \\
& \mathrm{V}=\text { Gaya yang bekerja sejajar } \\
& \quad \text { bidang }[\mathrm{N}] \\
& \mathrm{A}=\text { Luas bidang }\left[\mathrm{m}^{2}\right]
\end{aligned}
$$

Regangan dinyatakan sebagai pertambahan panjang per satuan panjang. Hukum Hooke menyatakan bahwa dalam batas-batas tertentu, tegangan pada suatu bahan adalah berbanding lurus dengan regangan. Secara matematis, regangan dapat ditulis sebagai berikut:

$$
\varepsilon=\frac{\delta}{L} .
$$

Hubungan antara tegangan dan regangan dapat ditulis sebagai berikut:

$$
\sigma=E . \varepsilon .
$$

Dimana:

$\varepsilon=$ Regangan

$\delta=$ Pertambahan panjang total [m]

$\mathrm{L}=$ Panjang mula-mula $[\mathrm{m}]$

$\mathrm{E}=$ Modulus elastisitas $\left[\mathrm{N} / \mathrm{m}^{2}\right]$

\section{METODE DAN TEKNIK PENGUKURAN}

Metodologi yang digunakan untuk menyelesaikan penelitian ini antara lain:

1. Studi Literatur

Penulis mencari dan mengkaji literatur yang sesuai dengan penelitian untuk memahami proses perancangan struktur base mesin induk $\mathrm{CNC}$ vertikal.

2. Pembuatan desain CAD

Desain CAD dibuat berdasarkan dokumen as built drawing dimana dimensi gambar menyesuaikan dimensi aktual.

3. Modifikasi dan optimasi desain 
Desain base mesin induk $\mathrm{CNC}$ vertikal yang didesain dari base mesin milling CNC yang pernah dibuat sebelumnya dimodifikasi dari segi ukuran dan strukturnya.

4. Analisa pembebanan statik

Penulis melakukan analisis kekuatan struktur base mesin induk $\mathrm{CNC}$ vertikal ketika menerima pembebanan statik.

5. Diskusi

Penulis melakukan diskusi setiap saat (jika diperlukan) dari awal penelitian sampai penelitian selesai dengan rekan satu tim peneliti dan berbagai pihak untuk memahami dan menentukan langkah selanjutnya.

\section{HASIL DAN PEMBAHASAN}

Mesin induk CNC vertikal secara umum terdiri dari 7 komponen utama, yaitu base, saddle, table, column, headstock, spindle dan motor spindle. Pada Tabel 4 berikut ini merupakan berat dari 5 komponen utama yang diatas struktur base mesin induk $\mathrm{CNC}$ vertikal dan berat benda kerja.

Tabel 4. Berat Komponen Utama Mesin Induk CNC Vertikal

\begin{tabular}{|c|c|c|}
\hline No & Komponen & Berat $[\mathbf{k g}]$ \\
\hline 1 & Benda Kerja & 2.000 \\
\hline 2 & Saddle & 1.600 \\
\hline 3 & Table & 1.500 \\
\hline 4 & Column & 1.900 \\
\hline 5 & Headstock & 1.170 \\
\hline 6 & Spindle & 120 \\
\hline 7 & Motor Spindle & 110 \\
\hline
\end{tabular}

(sumber: pengolahan data)

Pada Gambar 3 berikut merupakan pemosisian komponen mesin induk $\mathrm{CNC}$ vertikal secara umum.

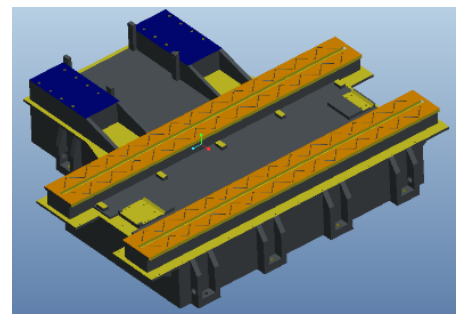

Keterangan :

Column + Headstock + Spindle + Motor Spindle

Benda Kerja + Saddle + Table

Gambar 3. Pemosisian Komponen Mesin Bubut CNC
Dalam pembebanan statik ini akan dibuat beberapa asumsi sebagai kondisi batas untuk memudahkan proses perhitungan dan analisis, antara lain:

1. Pembebanan akibat berat komponen yang diterima oleh base adalah dari Benda Kerja, Saddle, Table, Column, Headstock, Spindle, dan Motor Spindle.

2. Gaya berat yang diterima oleh base terdistribusi merata/tidak pada satu titik pada bagian base yang menerima pembebanan.

3. Nilai gravitasi $g=10 \mathrm{~m} / \mathrm{s} 2$.

4. Material base menggunakan carbon steel FC 20 dengan yield strength $140 \mathrm{MPa}$.

Pada Gambar 4 berikut merupakan gaya pembebanan pada struktur base mesin induk $\mathrm{CNC}$ vertikal.

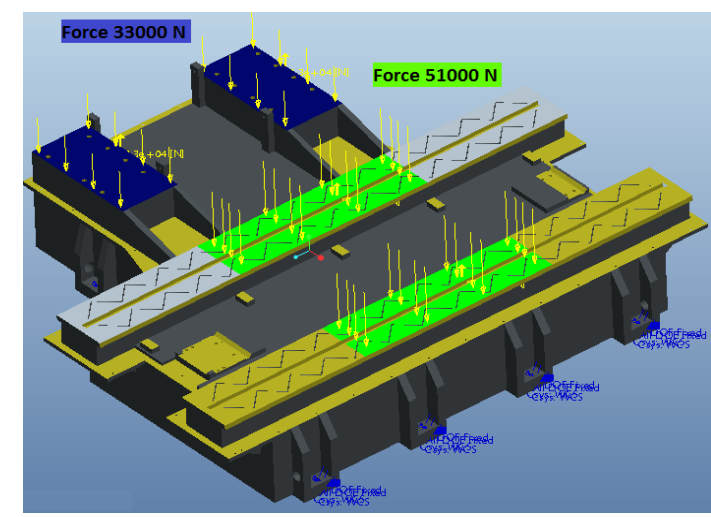

a. Saat beban di tengah

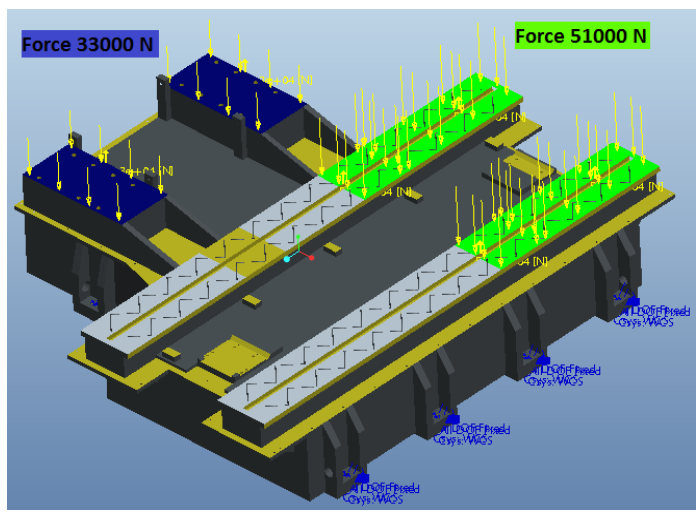

b. Saat beban di pinggir

Gambar 4. Gaya Pembebanan Base Mesin Induk CNC Vertikal

Besar dan arah gaya yang diberikan seperti pada Gambar 4 diaplikasikan pada base kemudian dilakukan analisis statik untuk melihat defleksi dan tegangan von mises untuk menganalisa apakah desain struktur tersebut 
mampu menahan beban yang diberikan, baik saat beban di tengah maupun di pinggir.

Berikut adalah hasil dari analisis statik pada desain base mesin induk $\mathrm{CNC}$ vertikal.

1. Analisis statik deformasi dengan pembebanan di tengah dan di pinggir (Gambar 5)

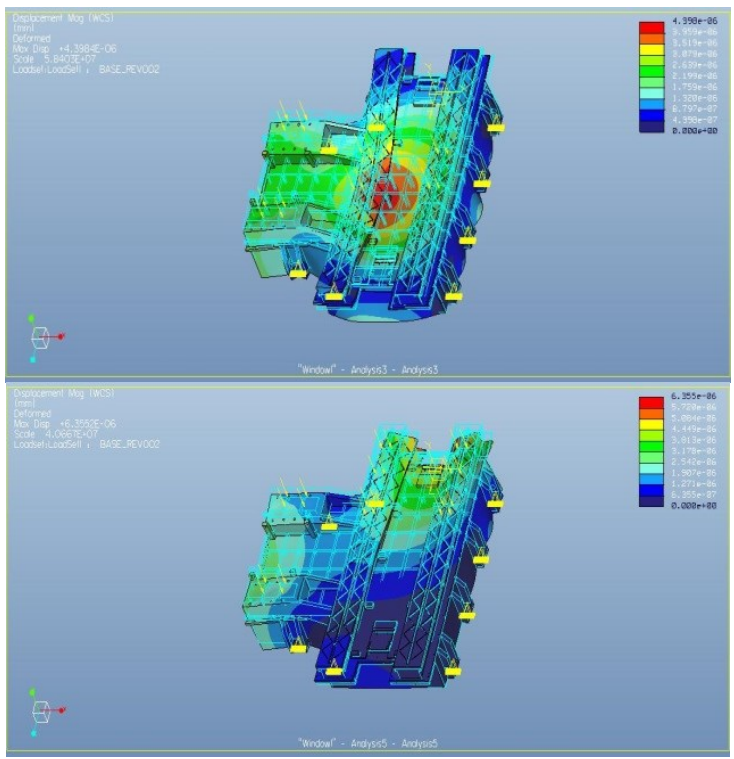

Gambar 5. Defleksi Statik Base Mesin Induk CNC Vertikal

2. Analisis statik Tegangan von mises dengan pembebanan di tengah dan di pinggir (Gambar 6)

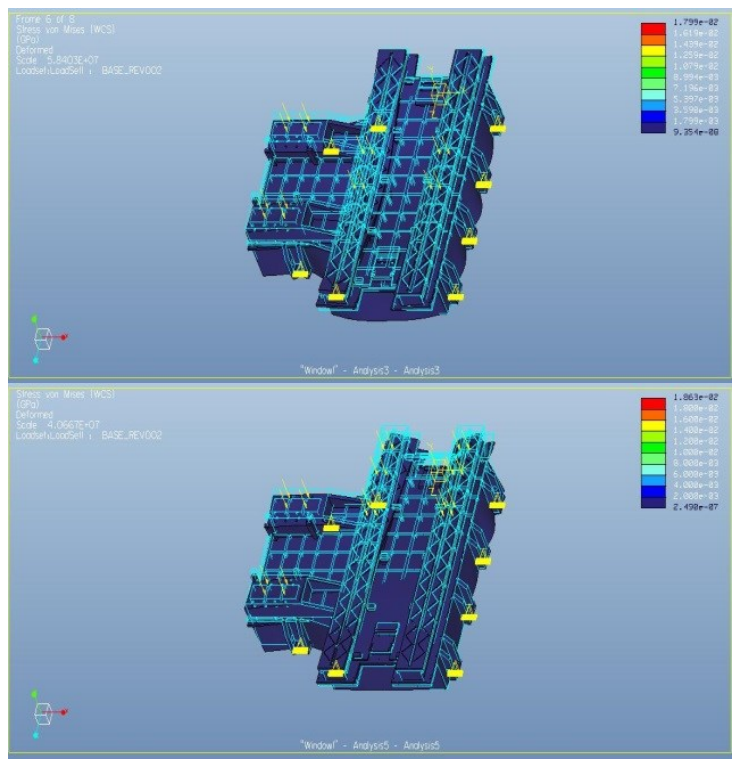

Gambar 6. Tegangan Von Mises Base Mesin Induk CNC Vertikal

Dari analisis pembebanan statik tersebut, ditampilkan pada Tabel 5 berikut:
Tabel 5. Hasil Analisis Statik Base Komponen Mesin Induk CNC Vertikal

\begin{tabular}{|c|c|c|c|c|}
\hline $\begin{array}{c}\text { Nama } \\
\text { Komponen }\end{array}$ & $\begin{array}{c}\text { Berat } \\
{[\mathbf{k g}]}\end{array}$ & Beban & $\begin{array}{c}\text { Defleksi } \\
\text { statik } \\
{[\boldsymbol{\mu} \mathbf{m}]}\end{array}$ & $\begin{array}{c}\text { Tegangan } \\
\text { von mises } \\
{[\mathbf{M P a}]}\end{array}$ \\
\hline \multirow{2}{*}{ Base } & 3.800 & $\begin{array}{c}\mathrm{di} \\
\text { tengah }\end{array}$ & 4,3980 & 17,9900 \\
\cline { 3 - 5 } & $\begin{array}{c}\text { di } \\
\text { pinggir }\end{array}$ & 6,4020 & 16,0200 \\
\hline
\end{tabular}

(sumber: pengolahan data)

Analisa pembebanan statik base mesin induk CNC vertikal menghasilkan tegangan von mises sebesar 17,99 Mpa saat beban di tengah dan 16,02 MPa saat beban di pinggir, nilai tersebut masih dibawah yield strength material yang dipakai yaitu sebesar $140 \mathrm{MPa}$, hal ini mengindikasikan bahwa desain struktur base tersebut mampu untuk mendistribusikan pembebanan yang dialaminya dengan baik.

Dari aspek deformasinya untuk base mesin induk $\mathrm{CNC}$ vertikal mengalami defleksi statik maksimal sebesar 4,398 $\mu \mathrm{m}$ saat beban di tengah dan 6,402 saat beban di pinggir, hal ini menunjukkan bahwa dari segi defleksi yang dialami, desain struktur base mempunyai tingkat kekakuan yang baik dan masih aman jika digunakan menurut analisa struktur yang telah dilakukan.

\section{KESIMPULAN}

Dari hasil dan pembahasan diatas dapat diambil beberapa kesimpulan sebagai berikut:

1. Desain struktur base masih aman menerima beban statik dari komponen lainnya dari mesin induk $\mathrm{CNC}$ vertikal yang dirancang.

2. Saat pembebanan di tengah, Tegangan von mises yang dihasilkan dari desain struktur base mesin induk $\mathrm{CNC}$ vertikal yang dirancang yaitu sebesar $17,99 \mathrm{MPa}$.

3. Saat pembebanan di pinggir, Tegangan von mises yang dihasilkan dari desain struktur base mesin induk $\mathrm{CNC}$ vertikal yang dirancang yaitu sebesar $16,02 \mathrm{MPa}$.

4. Saat pembebanan di tengah, Defleksi maksimal dari desain struktur base mesin induk CNC vertikal yang dirancang yaitu sebesar $4,398 \mu \mathrm{m}$.

5. Saat pembebanan di pinggir, Defleksi maksimal dari desain struktur base 
mesin induk CNC vertikal yang dirancang yaitu sebesar $6,402 \mu \mathrm{m}$.

6. Desain struktur base mesin induk $\mathrm{CNC}$ vertikal yang dirancang masih aman jika digunakan menurut analisa struktur, karena tegangan von mises yang dihasilkan masih dibawah yield strength material yang dipakai yaitu sebesar $140 \mathrm{MPa}$.

\section{DAFTAR PUSTAKA}

Y. Altintas, C. Brecher, M. Weck, S. Witt, Virtual machine tool, Annals of CIRP 54 (2005) 115-138

Agus Wibowo., Ahmad Taufiqur Rohman, Optimisasi Desain Ribbing pada Struktur Bed Mesin Bubut CNC terhadap Pengaruh Defleksi dan Frekuensi Pribadi, SNTM ITB (2016)

https://www.chegg.com/homeworkhelp/questions-and-answers/e220material-price-proposed-replace-castiron-casing-power-tool-one-preciselydimension-m-q30887901 (diakses tanggal 19 Oktober 2019).

http://www.engineeringenotes.com/metallurgy/ cast-iron/cast-irons-composition-andproperties-alloys-iron-metallurgy/26423 (diakses tanggal 19 Oktober 2019).

Joshi, PH., Machine Tools Handbook : Design and Operation, Tata McGraw-Hill, India, 2005.

Weck, Manfred, Handbook of Machine Tools Volume 2: Construction and Mathematical Analysis, John Wiley \& Sons, Inggris, 1984. 